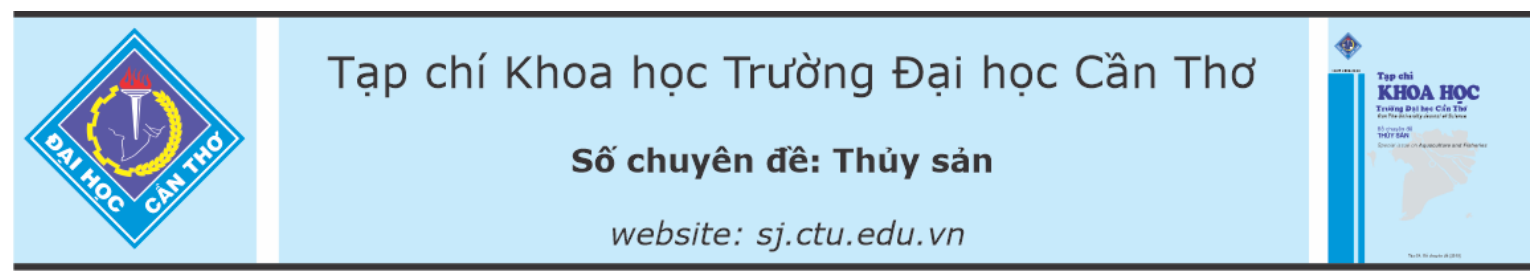

DOI:10.22144/ctu.jvn.2021.069

\title{
PHÂN LẬP VÀ TUYỂN CHỘN MỘT SỐ CHỦNG XẠ KHUẨN CÓ KHẢ NĂNG PHÂN HƯYY CHẤT HŨ̃U CƠं VÀ KHÁNG KHUẨN ỨNG DỤNG TRONG NUÔI TRỒNG THỦY SẢN
}

\author{
Phạm Thị Tuyết Ngân*, Vũ Hùng Hải, Vũ Ngọc Út và Huỳnh Trường Giang
}

Bộ môn Thủy sinh họ ứng dụng, Khoa Thủy sản, Truờng Đại học Cần Tho

*Nguoòi chịu trách nhiệm về bài viết: PhạmThịTuyết Ngân (email: pttngan@ctu.edu.vn)

\section{Thông tin chung:}

Ngày nhận bài: $22 / 02 / 2021$

Ngày nhận bài sủa: 07/05/2021

Ngày duyệt đăng: 01/06/2021

Title:

Isolation and selection of actinomycetes capable of biodegradation and antimicrobial activity in aquaculture

\section{Tù khóa:}

Hoạt tính enzyme, kháng khuẩn, phân lập, streptomyces, xạ khuẩn

\section{Keywords:}

Actinomycetes, antimicrobial activity, enzyme activity, isolation, streptomyces

\begin{abstract}
The The study is aimed to isolate and screen potential actinomycetes from shrimp pond sediments that being capable of biodegradation and antimicrobial activity against Vibrio parahaemolyticus in vitro. Total of 40 sediment samples were collected in extensive shrimp ponds located in Tra Vinh, Bac Lieu and Ca Mau province. Results showed that 161 strains were able to grow on Starch Casein Agar (SCA) medium, in which 54 strains were identified as Streptomyces genus with the characteristics of gram-positive cell, catalase positive, oxidase negative and spore formation. Out of the 54 Streptomyces isolates, 12 strains performed the antimicrobial activity against Vibrio parahaemolyticus with a mean inhibition zone ranged from 2.3 to $32.8 \mathrm{~mm}$, especially 04 strains, CM1.1, CM2.4, DH3.4 and TV1.4 possessed the largest zone. In addition, DH3.4 strain was greatly potential for the relatively high enzyme activities such as $\alpha$-amylase, protease and cellulase. Therefore, these strains could be used for in vitro and in vivo further experiments in aquaculture.
\end{abstract}

\section{TÓM TÁT}

Nghiên cưu được thực hiện nhằm phân lập và sàng lọc một số chủng xa khuẩn tù bùn đáy ao nuôi tôm có khả năng phân hủy hữu co và kháng Vibrio parahaemolyticus trong điều kiện in vitro. Tổng công 40 mẫu bùn được thu tù ao nuôi tôm ở Trà Vinh, Bạc Liêu và Cà Mau. Kết quả phân lập được 161 chủng có khả năng phát triển trên môi truờng Starch Casein Agar (SCA), trong đó 54 chủng có đặc điểm nhận dạng giống với giống Streptomyces với các đặc điểm hình thái nhu tế bào gram dưong, duong tính với catalase, âm tính với oxidase và có khả năng hình thành bào tử. Trong số 54 chủng, 12 chủng thể hiện hoạt tính kháng Vibrio parahaemolyticus với đường kính vòng vô trùng dao động 2,3-32,8 mm, trong đó 04 chủng CM1.1, CM2.4, DH3.4 và TV1.4 thể hiện hoạt tính kháng cao nhất. Bên cạnh đó, chủng DH3.4 được coi là tiềm năng với khả năng sinh hoạt tính enzyme $\alpha$-amylase, protease và cellulase tuonng đối cao. Do đó, các chủng này có thể được sủ dụng cho các nghiên cứu in vitro and in vivo ưng dụng trong nuôi trồng thủy sản. 


\section{GIỚI THIỆU}

Thủy sản ở Việt Nam nói chung và Đồng bằng sông Cửu Long nói riêng là ngành đang được đầu tư và phát triển mạnh. Tuy nhiên trong những năm gần đây, việc thâm canh hóa với mật độ cao kèm khí hậu thay đổi thất thường làm bùng phát dịch bệnh trên động vật thủy sản, chất lượng nước và môi trường nuôi bị ô nhiễm đã làm giảm sản lượng nuôi. Mặt khác, việc sử dụng thuốc kháng sinh để trị bệnh trên động vật thủy sản thường xuyên và không đúng liều lượng đã tạo ra một số dòng vi khuẩn kháng thuốc.

Vì vậy, cần phải có một giải pháp cải thiện chất lượng môi trường nuôi mà không ảnh hưởng đến động vật thủy sản và con người. Hiện nay, việc sử dụng vi sinh vật hữu ích vào trong nuôi trồng thủy sản nhằm khắc phục những vấn đề trên là một giải pháp đang được ứng dụng rộng rãi. Theo Bao and Shen (2005), hệ thống nuôi thủy sản bền vững cần có sự hiện diện của nhóm vi khuẩn có lợi (beneficial microorganisms), nhóm vi khuẩn này không chứa độc tố, không hiệu ứng phụ, không tồn lưu và không kháng kháng sinh, tuy nhiên nhóm vi khuẩn này hiệu quả trong việc cải thiện môi trường và tăng hệ miễ்n dịch của vật nuôi, giảm stress và duy trì trạng thái cân bằng của hệ sinh thái thủy vực. Xạ khuẩn được biết đến là một trong những đối tượng quan trọng nhất trong sản xuất các hợp chất có hoạt tính sinh học (Sanglier, 1993; Mitra et al., 2008). Xạ khuẩn là nhóm vi sinh vật phân bố rộng rãi trong đất, chúng tham gia vào các quá trình phân giải các hợp chât hữu cơ trong đất nhờ các hoạt chất enzyme như protease, amylase, cellulase,.... góp phần khép kín vòng tuần hoàn vật chất trong tự nhiên (Prakash, 2013). Đặc tính này còn được ứng dụng trong quá trình chế biến phân huỷ rác. Trong quá trình sống xạ khuẩn tiết ra nhiều chất có hoạt tính sinh học cao có khả năng kháng lại các loài vi sinh vật khác nhau bao gồm cả nấm và vi khuẩn. Trong số 23,000 hợp chất có hoạt tính sinh học được sản xuất từ vi sinh vật, hơn 10,000 hợp chất được phân lập từ xạ khuẩn (Watve et al., 2001). Trong khoảng hơn 8.000 chất kháng sinh được biết trên thế giới hiện nay thì có hơn $80 \%$ trong số đó có nguồn gốc từ xạ khuẩn. Việc tìm kiếm các chủng xạ khuẩn mới có khả năng ứng dụng cao trong nuôi trồng thủy sản và tìm ra loại môi trường để chúng phát triển tối ưu phục vụ cho ao nuôi tôm, cá là rất cần thiết. Để nghiên cứu việc ứng dụng các chủng xạ khuẩn trong thủy sản, đề tài "Phân lập và tuyển chọn một số chủng xạ khuẩn có khả năng phân hủy chất hữu cơ và kháng khuẩn ứng dụng trong nuôi trồng thủy sản" được tiến hành.

\section{PHƯƠNG PHÁP NGHIÊN CÚU}

\subsection{Phương pháp thu mẫu}

Các ao nuôi tôm thuộc khu vực của tỉnh Trà Vinh, Bạc Liêu, Cà Mau được chọn để thu mẫu. Mẫu bùn được thu bằng dụng cụ PVC $(\varnothing 49 \mathrm{~mm})$ theo mô tả của Somsiri et al. (2006). Hỗn hợp bùn thu bằng dụng cụ ống PVC được loại bỏ nước thông qua các lỗ trên thân ống, sau đó lớp bùn mặt có độ dày $2-5 \mathrm{~cm}$ được thu vào túi nhựa. Mẫu bùn được thu 4-5 điểm xung quanh ao, sau đó trộn đều các mẫu lại với nhau đề đồng nhất mẫu và bảo quản trong thùng lạnh, vận chuyển về phòng thí nghiệm để tiến hành xử lý và phân lập.

\subsection{Phân lập và nhận dạng xạ khuẩn}

Một gram mẫu bùn ao được pha loãng lần lượt $\left(10^{-1}, 10^{-2}, 10^{-3}\right)$ với nước muối sinh lý tiệt trùng $(0,85 \% \mathrm{NaCl})$ và trải trên môi trường đĩa thạch $\mathrm{SCA}$ (Starch Casein Agar) (bổ sung 1,5\% NaCl) được bổ sung nystatin $(25 \mu \mathrm{g} / \mathrm{mL})$ và nalidixic acid $(20$ $\mu \mathrm{g} / \mathrm{mL}$ ) để hạn chế sự phát triển của nấm và vi khuẩn khác (Takizawa et al., 1993). Đĩa thạch được ủ ở 30 ${ }^{\circ} \mathrm{C}$ khoảng 7 ngày. Sau đó, các khuẩn lạc với hình dạng và kích thước khác nhau được chọn để tách ròng trên môi trường thạch $\mathrm{SCA}$ đến khi thu được khuẩn lạc thuần, tiến hành nhuộm Gram (Hucker \& Conn, 1923) và kiểm tra phản ứng với catalase, oxidase. Các đặc điểm sinh lý và sinh hóa được xác định dựa theo cẩm nang của Cowan and Steels (Barrow \& Feltham, 1993) kết hợp với sử dụng bộ kit API 20E (BioMerieux, France). Các chủng Gram $(+)$ và dương tính với Catalase, Oxidase âm tính, được chọn nuôi tăng sinh và trữ lạnh $-80^{\circ} \mathrm{C}$ với $25 \%$ glycerol cho các nghiên cứu sau.

\subsection{Sàng lọc các chủng xạ khuẩn có hoạt tính kháng khuẩn}

Thí nghiệm khảo sát khả năng sinh hoạt tính kháng khuẩn bằng phương pháp cấy vệt vuông góc theo mô tả trước đây của Chythanya et al. (2002) và Das et al. (2010). Cụ thể, các chủng xạ khuẩn phân lập được cấy vào trung tâm đĩa thạch NA (bổ sung $1 \% \mathrm{NaCl}$ ) một đường thẳng (rộng khoảng $0,5 \mathrm{~cm}$ ), ủ đĩa ở $30^{\circ} \mathrm{C}$ trong 7 ngày. Chủng vi khuẩn gây bệnh $V$. parahaemolyticus sử dụng trong nghiên cứu được phân lập từ tôm bị bệnh hoại tử gan tụy cấp (AHPND) và lưu trữ tại phòng thí nghiệm Vi sinh vật hữu ích- Bộ môn Thủy sinh học Ứng dụng Khoa Thủy sản - Trường Đại học Cần Thơ được phục hồi trên môi trường $\mathrm{NA}$ (bồ sung $1,5 \% \mathrm{NaCl}$ ). Sau đó cấy chủng vi khuẩn Vibrio một đường vuông góc $90^{\circ}$ với vệt cấy của xạ khuẩn. Quan sát khả năng đối kháng sau 24 giờ ở $30^{\circ} \mathrm{C}$ bằng cách đo đường vô 
trùng giữa chủng xạ khuẩn với các chủng vi khuẩn Vibrio. Mức độ kháng được đánh giá thông qua đường kính vòng vô trùng so với tiêu chuẩn của Lorian (1995) (Kháng: $\leq 9 \mathrm{~mm}$; Trung bình: $\geq 10$ $13 \mathrm{~mm}$; Nhạy: $\geq 14 \mathrm{~mm}$ )

\section{4. Đánh giá hoạt tính enzyme ngoại bào}

Các chủng xạ khuẩn kháng $V$. parahaemolyticus được chọn để tiến hành đánh giá hoạt tính enzyme ngoại bào trong điều kiện in vitro:

Hoạt tính protease: các chủng xạ khuẩn chọn lọc được nuôi trong môi trường khoáng cơ bản (bao gồm glucose $0,5 \mathrm{~g} / \mathrm{L} ; \mathrm{KNO}_{3} 0,6 \mathrm{~g} / \mathrm{L}$; peptone $10 \mathrm{~g} / \mathrm{L}$; $\mathrm{MgSO}_{4} .7 \mathrm{H}_{2} \mathrm{O} 0,5 \mathrm{~g} / \mathrm{L}, \mathrm{NaCl} 10 \mathrm{~g} / \mathrm{L} ; \mathrm{CaCl}_{2} 1,0 \mathrm{~g} / \mathrm{L}$ và $\mathrm{K}_{2} \mathrm{HPO}_{4} 0,5 \mathrm{~g} / \mathrm{L}$ ) bổ sung $1 \%$ casein (Abdullah Al-Dhabi et al., 2020). Sau 7 ngày nuôi ở $30^{\circ} \mathrm{C}$ tiến hành thu dịch nổi (Cell-free supernatant, $\mathrm{CFS}$ ) bằng phương pháp ly tâm lạnh ở vận tốc 8.500 vòng trong 10 phút ở $4^{\circ} \mathrm{C}$ và xác định hoạt tính enzyme protease dựa theo mô tả Huynh et al. (2018) như sau: $100 \mu \mathrm{L}$ dịch CFS ủ với $100 \mu \mathrm{L}$ dung dịch $1 \%$ casein (pha trong dung dịch đệm Tris- $\mathrm{HCl}, \mathrm{pH} 7,0)$ trong 10 phút ở $37^{\circ} \mathrm{C}$ và $500 \mu \mathrm{L}$ dung dịch $5 \%$ Trichloroacetic acid được thêm vào để ngừng phản ứng. Sau 20 phút, hỗn hợp trên được ly tâm ở tốc độ $3.000 \mathrm{rpm}$ trong 10 phút ở $4^{\circ} \mathrm{C}$ và thu phần dịch nồi bên trên để xác định hoạt tính enzyme theo phương pháp Lowry (1951). Một unit (UI) enzyme tương ứng với lượng enzyme phóng thích $1 \mu \mathrm{g}$ tyrosine ở cùng điều kiện chuẩn.

Hoạt tính $\alpha$-amylase: dịch nổi CFS của các chủng xạ khuẩn sau 7 ngày nuôi trong môi trường sinh tổng hợp amylase (Kafilzadeh \& Dehdari, 2015) bao gồm $6 \mathrm{~g} / \mathrm{L}$ bacteriological peptone; 0,5 $\mathrm{g} / \mathrm{L} \mathrm{MgSO}_{4} .7 \mathrm{H}_{2} \mathrm{O} ; 0,5 \mathrm{~g} / \mathrm{L} \mathrm{KCl} ; 10 \mathrm{~g} / \mathrm{L} \mathrm{NaCl}$ và 1 $\mathrm{g} / \mathrm{L}$ starch. Hoạt tính $\alpha$-amylase được xác định theo mô tả của Bernfeld (1955) với một vài thay đổi. Cụ thể, phản ứng gồm $100 \mu \mathrm{L}$ dịch enzyme vi khuẩn ủ với $100 \mu \mathrm{L}$ dung dịch $1 \%$ soluble starch (pha trong dung dịch đệm $\mathrm{NaH}_{2} \mathrm{PO}_{4} 20 \mathrm{mM}$ và $\mathrm{NaCl} 6,7 \mathrm{mM}$ ) trong ống nghiệm thủy tinh ở $37^{\circ} \mathrm{C}$ trong 15 phút. Sau đó, phản ứng sẽ tạo màu với $200 \mu \mathrm{L}$ dung dịch thuốc thử DNS theo phương pháp Miller (1959) và xử lý nhiệt ở $100^{\circ} \mathrm{C}$ trong 5 phút. Các ống nghiệm được làm lạnh và đo độ hấp thụ ở bước sóng 540 $\mathrm{nm}$. Nồng độ enzyme phóng thích $1 \mu \mathrm{mol}$ maltose ở cùng điều kiện chuẩn được xác định như một unit enzyme amylase.

Hoạt tính cellulase: xạ khuẩn nuôi trong môi trường khoáng cơ bản (Fatokun et al., 2016) gồm 1,0 $\mathrm{g} / \mathrm{L} \mathrm{KCl} ; 1,0 \mathrm{~g} / \mathrm{L} \mathrm{NaNO}_{3} ; 1,0 \mathrm{~g} / \mathrm{L} \mathrm{K}_{2} \mathrm{HPO}_{4} ; 0,5 \mathrm{~g} / \mathrm{L}$ $\mathrm{MgSO}_{4} ; 0,5 \mathrm{~g} / \mathrm{L}$ yeast extract; $10 \mathrm{~g} / \mathrm{L} \mathrm{NaCl}$ ) bổ sung $1 \%$ Sodium carboxymethyl cellulose (Na-CMC). Sau 7 ngày nuôi, thu dịch CFS bằng phương pháp ly tâm để xác định hoạt tính enzyme theo mô tả Ghose (1987) có điều chỉnh. Phản ứng bao gồm $0,5 \mathrm{~mL}$ dung dịch $1 \%$ Sodium carboxymethyl cellulose (được chuẩn bị trong dung dịch đệm Citrate $0,05 \mathrm{M}$; $\mathrm{pH} 5,0)$ và $0,5 \mathrm{~mL}$ dịch enzyme vi khuẩn được ủ ở $50^{\circ} \mathrm{C}$ trong 30 phút, sau đó Thêm $1,5 \mathrm{~mL}$ dung dịch thuốc thử DNS (Miller, 1959) vào phản ứng và đun nóng $100^{\circ} \mathrm{C}$ trong 10 phút. Sau đó, đo độ hấp thụ ở bước sóng $540 \mathrm{~nm}$ bằng phương pháp so màu quang phổ. Một unit enzyme được xác định như lượng enzyme phóng thích $1 \mu \mathrm{mol}$ glucose ở cùng điều kiện chuẩn.

\subsection{Phương pháp xử lý số liệu}

Số liệu được tính giá trị trung bình và độ lệch chuẩn bằng chương trình Excel và phân tích thống kê ANOVA một nhân tố sử dụng phép thử Duncan bằng chương trình SPSS 16,0 ở mức ý nghĩa thống kê $(\mathrm{p}<0,05)$.

\section{KẾT QUẢ VÀ THẢO LUẬN}

\subsection{Phân lập, sàng lọc và nhận dạng các giống xạ khuẩn}

Tổng cộng 162 chủng xạ khuẩn được phân lập từ mẫu bùn ao nuôi tôm (12 mẫu ở Trà Vinh, 11 mẫu ở Bạc Liêu và 17 mẫu ở Cà Mau), trong đó 51 chủng có nguồn gốc từ ao tôm thuộc tỉnh Trà Vinh, 54 chủng từ mẫu bùn ao tôm ở Bạc Liêu và 57 chủng từ bùn ao tôm thuộc tỉnh Cà Mau. Hầu hết các chủng phân lập phát triển trên môi trường SCA ở $30^{\circ} \mathrm{C}$ sau 7 ngày nuôi với các đặc điểm hình thái như kích thước khuẩn lạc dao động 1,1-2,8 mm, rìa không đều, màu sắc đa dạng từ màu trắng phấn $(55 \%)$, xám (19\%), vàng $(14,2 \%)$, nâu $(6,2 \%)$, đỏ $(5,6 \%)$. Dựa theo miêu tả của Williams and Cross (1971), có tổng cộng 54 chủng có đặc điểm nhận dạng giống với giống Streptomyces.

Bên cạnh đó, kết quả kiểm tra sinh hóa cho thấy 54 chủng đều bắt màu với thuốc nhuộm crystal violet chứng tỏ các chủng này là vi khuẩn gram dương. Khi quan sát hình dạng tế bào dưới vật kính $100 \mathrm{X}$ hầu hết tế bào có dạng hình chuỗi sợi dài $(87 \%)$, một số hình que và hình cầu (13\%). Các đánh giá kiểm tra sinh hóa khác cho kết quả dương tính với catalase, âm tính với oxidase và có khả năng hình thành bào tử (Hình 1 và Bảng 2). Các chủng phân lập có khả năng phát triển ở ngưỡng $\mathrm{pH}$ từ 411 và ở nồng độ muối lên đến $5 \% \mathrm{NaCl}$. 
Nhiều nghiên cứu trước đây đã phân lập các loài thuộc giống Streptomyces từ nhiều nguồn khác nhau (bùn đáy, đất canh tác, ruột cá,...) và phát triển thành các probiotic sử dụng hiệu quả trong nuôi tôm biển (Das et al., 2010; Vignesh et al., 2019; MazónSuástegui et al., 2020). Trong nghiên cứu của Bảng 1. Kết quả kiểm tra sinh hóa bằng bộ kit $\mathrm{API} 20^{\mathrm{E}}$

\begin{tabular}{|c|c|c|c|c|}
\hline Đặc điểm & Chủng TV1.4 & Chủng DH3.4 & $\begin{array}{c}\text { S. caldifontis } \\
\text { (Amin et al., 2016) }\end{array}$ & $\begin{array}{c}\text { S. drosdowiczii } \\
\text { (Amin et al., 2016) }\end{array}$ \\
\hline Hình dạng tế bào & Cầu & Chuỗi sợi & Chuỗi sợi & Chuỗi sợi \\
\hline Màu sắc khuẩn ty & Đỏ & Trắng & Trắng phấn & Xám \\
\hline Di động & - & - & - & - \\
\hline Bào tử & + & + & + & + \\
\hline Gram & + & + & + & + \\
\hline Catalase & + & + & + & - \\
\hline Oxidase & - & - & - & - \\
\hline $5^{\circ} \mathrm{C}$ & - & - & - & - \\
\hline $50^{\circ} \mathrm{C}$ & + & + & + & + \\
\hline pH 4 & + & + & - & - \\
\hline pH 6 & + & + & + & + \\
\hline pH 9 & + & + & + & + \\
\hline $\mathrm{pH} 11$ & + & + & - & - \\
\hline $0 \% \mathrm{NaCl}$ & + & + & + & + \\
\hline $5 \% \mathrm{NaCl}$ & + & + & + & + \\
\hline Lactose & - & + & - & - \\
\hline Arginine dihydrolase & + & + & + & + \\
\hline Lysine decarboxylase & - & - & + & - \\
\hline Ornithine decarboxylase & - & - & + & - \\
\hline Citrate utilization & + & + & + & + \\
\hline $\mathrm{H} 2 \mathrm{~S}$ production & - & - & ND & ND \\
\hline Urease & - & - & + & - \\
\hline Tryptophane & + & + & + & + \\
\hline Indole & - & + & + & + \\
\hline Voges proskauer & - & - & + & + \\
\hline Gelatinase & + & + & + & - \\
\hline Glucose & + & + & + & - \\
\hline Manniton & - & - & + & - \\
\hline Inositol & - & - & - & - \\
\hline Sorbitol & + & - & - & - \\
\hline Rhamnose & - & - & - & - \\
\hline Saccharose & + & + & + & - \\
\hline Melibiose & - & - & - & - \\
\hline Amygdalin & - & - & + & + \\
\hline Arabinose & - & $+/-$ & + & + \\
\hline
\end{tabular}

García-Bernal et al. (2015) cho thấy 31 chủng được phân lập từ bùn đáy biển với màu sắc khuẩn lạc đa dạng từ trắng, hồng, vàng và tím. Các chủng phân lập có khả năng phát triển ở nồng độ $\mathrm{pH}$ lớn hơn 3 và nồng độ muối $\mathrm{NaCl} 10 \%$ trên môi trường nuôi cấy.

Chú thich: (+) duoong tính, (-) âm tính, (+/-) có thể duơng hoặc âm tính, (ND) không xác định 

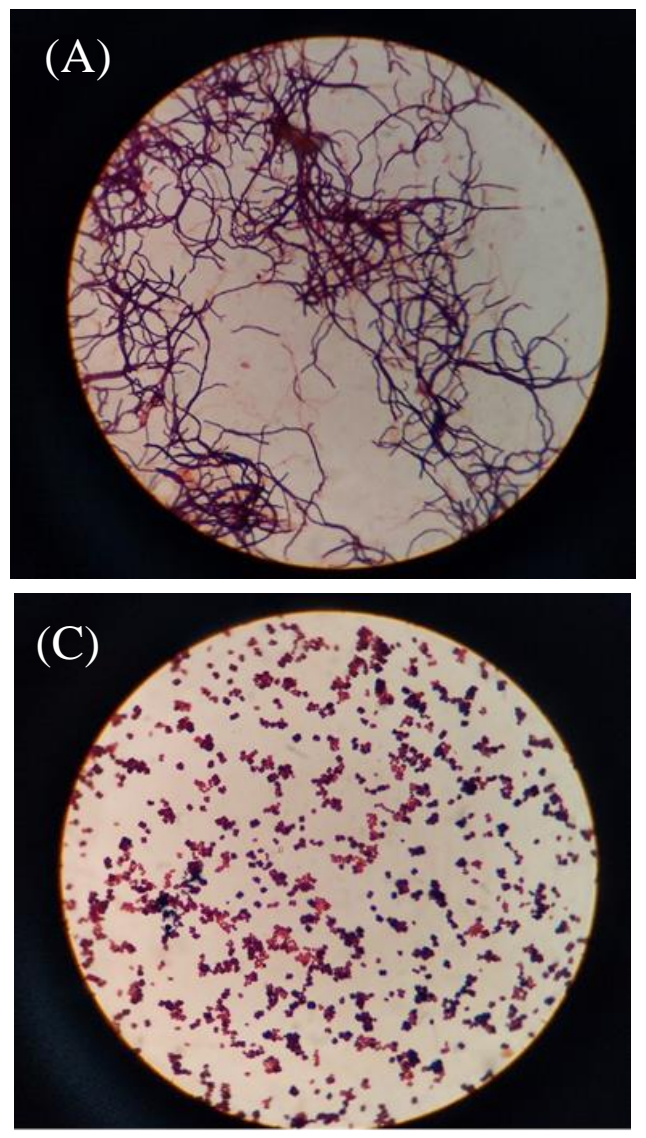

Hình 1. Khuẩn lạc xạ khuẩn trên môi trường $\mathrm{SCA}(\mathrm{B}, \mathrm{D})$ và kết quả nhuộm Gram $(\mathrm{A}, \mathrm{C})$

\subsection{Sàng lọc các chủng có hoạt tính kháng khuẩn Vibrio parahaemolyticus}

Kết quả sàng lọc 54 chủng bằng phương pháp cấy vệt vuông góc cho thấy có 13 chủng có khả năng kháng $V$. parahaemolyticus bao gồm 9 chủng kháng yếu (CN2.5, BL2.3, CN6.1, BL1.3, TV2.1, CN2.3, TV3.2, CN4.2 và NH2.1); 1 chủng kháng trung bình (CM1.1) và 3 kháng mạnh (CM2.4, DH3.4 và TV1.4) (Lorian, 1995). Đường kính kháng khuẩn của 13 chủng này dao động từ 2,3-32,8 $\mathrm{mm}$ (Bảng 2 và Hình 2). Nguyễn Xuân Cảnh và ctv. (2016) đã nghiên cứu về khả năng kháng $V$. paraheamolyticus của 96 chủng xạ khuẩn bằng phương pháp khuếch tán đĩa thạch. Kết quả tác giả đã sàng lọc được 3 chủng xạ khuẩn có khả năng đối kháng với vi khuẩn gây bệnh, trong số đó chủng 25.2 (Streptomyces aureofaciens) có khả năng đối kháng mạnh với đường kính dòng vô khuẩn là $15 \mathrm{~mm}$ thấp hơn kết quả nghiên cứu của chúng tôi (chủng xạ khuẩn TV1.4 có vòng kháng khuẩn $32,8 \mathrm{~mm}$ ). Thê vào đó trong những năm gần đây, đã có một số công bố trên thế giới về việc tìm ra các chủng xạ khuẩn có khả năng đối kháng với $V$. parahaemolyticus. So sánh
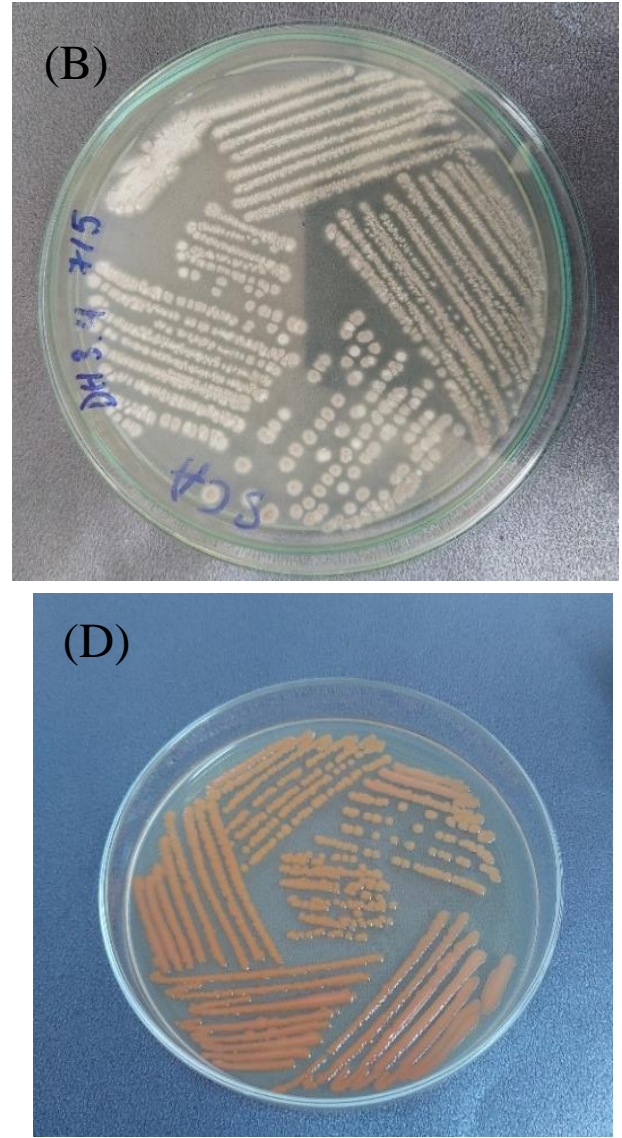

với những kết quả này và trước đây, chủng xạ khuẩn TV1.4 trong nghiên cứu này có hoạt tính kháng khuẩn tương đối mạnh (Selvakumar et al., 2010).

Bảng 2. Đường kính vòng kháng khuẩn $V$. parahaemolyticus

\begin{tabular}{ccr}
\hline STT & Chủng phân lập & $\begin{array}{r}\text { Đường kính vòng } \\
\text { kháng (mm) }\end{array}$ \\
\hline 1 & CN2.5 & $2,3 \pm 0,58$ \\
2 & BL2.3 & $3,3 \pm 0,50$ \\
3 & CN6.1 & $3,3 \pm 0,58$ \\
4 & BL1.3 & $4,2 \pm 0,72$ \\
5 & TV2.1 & $6,3 \pm 0,58$ \\
6 & CN2.3 & $6,5 \pm 0,50$ \\
7 & TV3.2 & $7,3 \pm 1,15$ \\
8 & CN4.2 & $7,7 \pm 0,58$ \\
9 & NH2.1 & $7,7 \pm 0,58$ \\
10 & CM1.1 & $10,3 \pm 0,58$ \\
11 & CM2.4 & $14,3 \pm 0,58$ \\
12 & DH3.4 & $24,8 \pm 0,76$ \\
13 & TV1.4 & $32,8 \pm 1,04$ \\
\hline
\end{tabular}

Ghi chú: Kháng: $\leq 9 \mathrm{~mm}$; Trung bình: $\geq 10-13 \mathrm{~mm}$; Nhay: $\geq 14 \mathrm{~mm}$ (Lorian, 1995) 

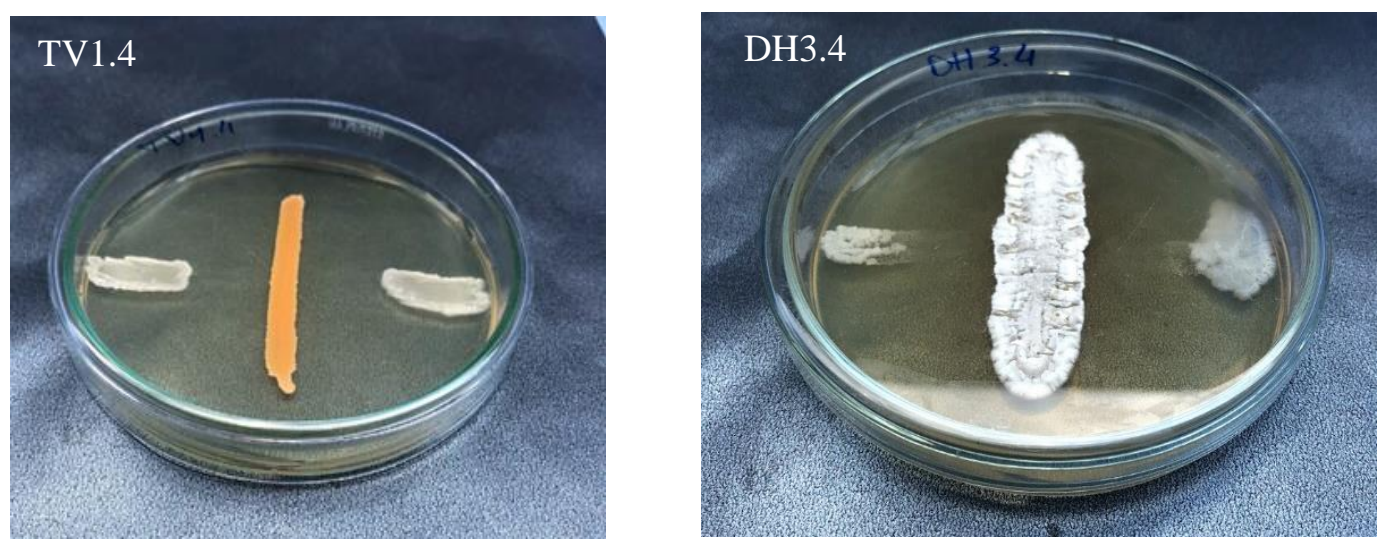

Hình 2. Khả năng kháng Vibrio parahaemolyticus bằng phương pháp cấy vệt vuông góc

\subsection{Hoạt tính enzyme ngoại bào}

Sau khi kiểm tra khả năng kháng $V$. parahaemolyticus, 4 chủng có kết quả hoạt tính cao nhất (CM1.1, CM2.4, DH3.4, TV1.4) được chọn để kiểm tra hoạt tính enzyme ngoại bào (Hình 3). Kết quả đánh giá cho thấy hoạt tính protease của chủng TV1.4 $(183,9 \pm 10,5 \mathrm{U} / \mathrm{mL})$ và $\mathrm{DH} 3.4(174,9 \pm 8,5$ $\mathrm{U} / \mathrm{mL}$ ) cao hơn và khác biệt có ý nghĩa so với các chủng còn lại $(p<0,05)$. Bên cạnh đó, hoạt tính $\alpha-$

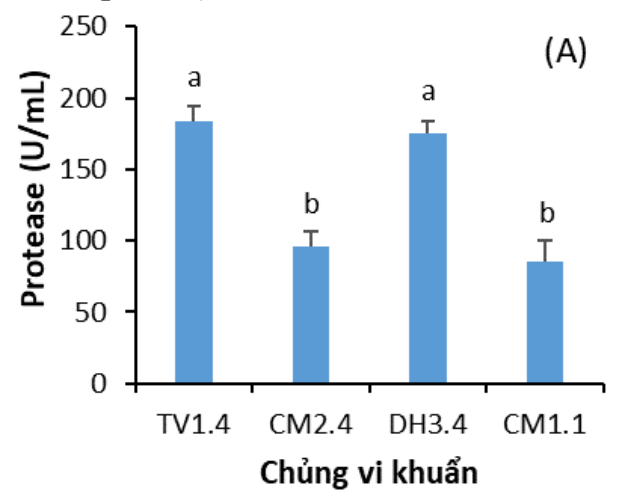

amylase của chủng DH3.4 đạt giá trị cao nhất $(262,7 \pm 20,7 \mathrm{U} / \mathrm{mL})$ trong khi đó không có sự khác biệt ý nghĩa $(\mathrm{p}>0,05)$ giữa hai chủng TV1.4 và CM1.1. Kết quả ghi nhận hoạt tính cellulose cho thấy chủng $\mathrm{CM} 2.4$ và $\mathrm{DH} 3.4$ đạt giá trị lần lượt là $119 \pm 7,6 \mathrm{U} / \mathrm{mL}, 84 \pm 7,7 \mathrm{U} / \mathrm{mL}$, cao hơn có ý nghĩa $(\mathrm{p}<0,05)$ so với các chủng còn lại và không có sự khác biệt giữa hai chủng TV1.4 và CM1.1 (p>0,05).

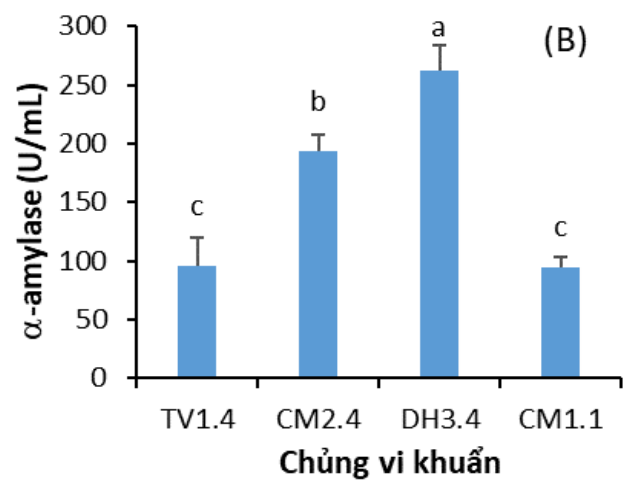

(C)

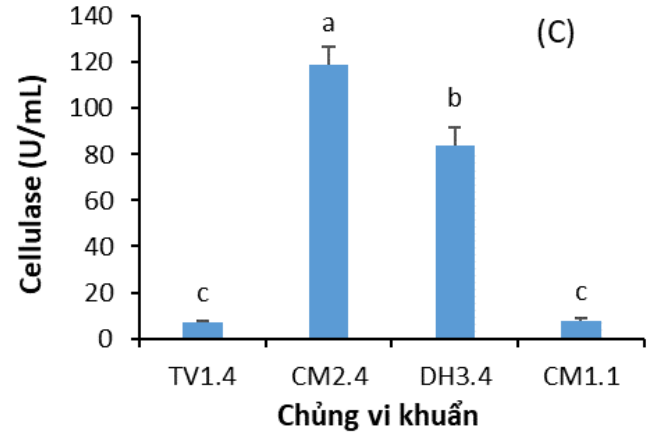

Hình 3. Hoạt tính enzyme ngoại bào protease $(\mathrm{A})$, amylase $(\mathrm{B})$ và cellulase $(\mathrm{C})$ của các chủng vi khuẩn chọn lọc 
Trong báo cáo của Al-Dhabi et al. (2020), hoạt tính enzyme protease của chủng Streptomyces sp. Al-Dhabi-49 sau 5 ngày nuôi cấy đạt giá trị $174 \pm$ $12,1 \mathrm{U} / \mathrm{mL}\left({ }^{\circ} 40^{\circ} \mathrm{C}\right)$, trong khi đó nghiên cứu của Dastager et al. (2008) cho thấy hoạt tính enzyme của vi khuẩn Streptomyces gulbargensis sp. Nov. là $121,8 \mathrm{U} / \mathrm{mL}$ sau 48 giờ nuôi ở $45^{\circ} \mathrm{C}$. Ngoài ra, hoạt tính $\alpha$-amylase của chủng Streptomyces fragilis DA7-7 theo báo cáo trước đây là $911,48 \mathrm{U} / \mathrm{mL}$ (Nithya et al., 2017) sau 3 ngày nuôi ở $28^{\circ} \mathrm{C}$ trong môi trường ISP2. Hơn nữa, chủng Streptomyces longispororuber $\mathrm{C} 188$ được kiểm tra hoạt tính cellulase đạt giá trị $15490 \mathrm{U} / \mathrm{L}$ (tương ứng 15,49 $\mathrm{U} / \mathrm{mL}$ ) sau 4 ngày nuôi ở $30^{\circ} \mathrm{C}$ trong môi trường CMC bổ sung $1 \%$ Corn Steep Liquor (Mahmoud et al., 2014). Trong nghiên cứu hiện tại, cả 4 chủng khảo sát đều cho kết quả hoạt tính enzyme cao hơn so với các kết quả nghiên cứu trước đây. Dựa vào kết quả ghi nhận, cả 3 chủng TV1.4, CM2.4 và DH3.4 với hoạt tính enzyme và khả năng kháng khuẩn mạnh nhất cho thấy đây là những chủng tiềm năng để chọn lọc và tiến hành các thí nghiệm tiếp theo.

\section{KẾT LUẬN}

Ba chủng xạ khuẩn TV1.4, CM2.4 và DH3.4 có khả năng kháng Vibrio parahaemolyticus mạnh nhất dựa vào đường kính của vòng kháng khuẩn. Đồng thời, cả ba chủng đều có hoạt tính enzyme mạnh, đặc biệt là chủng xạ khuẩn $\mathrm{DH} 3.4$ có cả ba hoạt tính enzyme protease, amylase và cellulase.

\section{LỜI CẢM TẠ}

Đề tài này được tài trợ bởi Dự án Nâng cấp Trường Đại học Cần Thơ VN14-P6 bằng nguồn vốn vay ODA từ Chính phủ Nhật Bản.

\section{TÀI LIỆU THAM KHẢO}

Al-Dhabi, N. A., Esmail, G. A., Ghilan, A. K. M., \& Arasu, M. V. (2020). Isolation and screening of Streptomyces sp. Al-Dhabi-49 from the environment of Saudi Arabia with concomitant production of lipase and protease in submerged fermentation. Saudi Journal of Biological Sciences, 27(1), 474-479.

Bao, X., \& Shen, W. (2005). Manufacture and application of micro cologicalagents. In: www.BIOX.CN:4-16.

Barrow, G. H., \& Feltham, R. K. A. (1993). Cowan and Steel's Manual for Identification of Medical Bacteria. 3rd Edition, Cambridge University Press, Cambridge, 331.

Bernfeld, P. (1955). Amylase, $\alpha$ and $\beta$. In: Colowick S. P., Kaplan N. O., editors. Methods in
Enzymology. New York, NY, USA: Academic Press. 1: 149-158.

Chythanya, R., Karunasagar, I., Karunasagar, I. (2002). Inhibition of shrimp pathogenic Vibrios by a marine Pseudomonas I-2 strain.

Aquaculture, 208: 1-10

Das, S., Ward, L. R., \& Burke, C. (2010). Screening of marine Streptomyces spp. for potential use as probiotics in aquaculture. Aquaculture, 305, 32-41.

Dastager, S. G., Dayanand, A., Li, W. J., Kim, C. J., Lee, J. C., Park, D. J., Tian, X. P., \& Raziuddin, Q. S. (2008). Proteolytic Activity from an AlkaliThermotolerant Streptomyces gulbargensis sp. nov. Current Microbiology, 57(6), 638.

García-Bernal, M., Campa-Cordova, A. I., SaucedoLastra, P. E., Casanova-Gonzalez, M., MedinaMarrero, R., \& Mazon-Suastegui, J. M. (2015). Isolation and in vitro selection of actinomycetes strains as potential probiotics for aquaculture. Veterinary World, 8(2), 170-176.

Ghose, T. K. (1987). Measurement of cellulose activities. Pure Appl Chem, 59(2), 257-268.

Hucker, G. J. and Conn, H. J. (1923). Biology; Bacteria; Pararosanilin; Dye; NYSAES; Gram. New York Agricultural Experiment Station.

Huynh, T. G., Chi, C. C., Nguyen, T. T., Hien, T. T. T., Cheng, A. C. \& Liu, C. H. (2018). Effects of synbiotic containing Lactobacillus plantarum 740 and galacto oligosaccharide on the growth performance of white shrimp, Litopenaeus vannamei. Aquaculture Research, 49, 2416 2428.

Kafilzadeh, F. and Dehdari, F. (2015). Amylase activity of aquatic Actinomycetes isolated from the sediments of mangrove forests in south of Iran. The Egyptian Journal of Aquatic Research, 41(2), 197-201.

Lorian, V. (1995). The need for surveillance for antimicrobial resistance. Infection control \& hospital epidermiology, 16(11), 638-64.

Lowry, O. H., Rosebrough, N. J., Farr, A. L. and Randall, R. J. (1951). Protein measurement with the Folin phenol reagent. The Journal of Biological Chemistry, 193, 265-275.

Mahmoud, A. M. Y., Asif, A. M. J. F. and Hani, Z. A. (2014). Production, purification and characterization of cellulase from Streptomyces sp. African Journal of Microbiology Research, 8(4), 348-354.

Mazón-Suástegui, J. M., Salas-Leiva, J. S., MedinaMarrero, R., Medina-García, R., \& GarcíaBernal, M. (2020). Effect of Streptomyces probiotics on the gut microbiota of Litopenaeus vannamei challenged with Vibrio parahaemolyticus. Microbiology Open, 9, 967. 
Miller, G. L. (1959). Use of dinitrosalicylic acid reagent for determination of reducing sugars. Analytical Chemistry, 3, 426-428.

Mitra, A., Santra, S. C. \& Mukharjee, J. (2008). Distribution of actinomycetes, the antagonistic behavior and the Physio - chemical characteristic of the worlds lagest tidal mangrove forest. Applied Microbial Biotechnology, 80, 685- 695.

Nguyễn Xuân Cảnh, Hồ Tú Cường, Nguyễn Thị Định \& Phạm Thị Hiếu. (2016). Nghiên cứu chủng xạ khuẩn có khả năng đối kháng với vi khuẩn Vibrio paraheamolyticus gây bệnh trên tôm. Tạp chí Khoa học Nông Nghiệp Việt Nam, 14(11), 1809-1816.

Nithya, K., Muthukumar, C., Kadaikunnan, S., Alharbi, N. S., Khaled, J. M. \& Dhanasekaran, D. (2017). Purification, characterization, and statistical optimization of a thermostable $\alpha$ amylase from desert actinobacterium Streptomyces fragilis DA7-7. 3 Biotech, 7(5), 350.

Prakash, D., Nawani, N., Prakash, M., Bodas, M., Mandal, A., Khetmalas, M. \& Kapadnis, B. (2013). Actinomycetes: a repertory of green catalysts with a potential revenue resource. BioMed Research International: 1-8.

Sanglier, J., Haag, H., Huck, T. and Fehr, T. (1993). Novel bioactive compounds from Actinomycetes. Research in Microbiology, 144(8), 661-663.
Selvakumar D., Arun K., Suguna S., Kumar D., Dhevendaran K. (2010). Bioactive potential of Streptomyces against fish and shellfish pathogens. Iranian Journal of Microbiology, 2(3), 157 - 164.

Somsiri, T., Oanh, D. T. H., Chinabut, S., Phuong, N. T., Shariff, M., Yusoff, F. M., \& Teale, A. (2006). A simple device for sampling pond sediment. Aquaculture, 258(1), 650-654.

Takizawa, M., Hill, R. T., \& Colwell, R. R. (1993). Isolation and diversity of actinomycetes in the Chesapeake Bay. Applied and Environmental Microbiology, 59, 997-1002

Vignesh, A., Ayswarya, S., Gopikrishnan, V., \& Radhakrishnan, M. (2019). Bioactive potential of actinobacteria isolated from the gut of marine fishes. Indian Journal of Geo Marine Sciences, 48 (08), 1280-1285.

Vũ Thế Trụ, 2003. Cải tiến kĩ thuật nuôi tôm tại Việt Nam. Nhà xuất bản Thành phố Hồ Chí Minh: Nông nghiệp.

Watve, M. G., Tickoo, R., Jog, M. M and Bhole B. D. (2001). How many antibiotics are produced by the genus Streptomyces? Archives of Microbiology, 176(5), 386 - 390.

Williams, S. T. and Cross, T. (1971). Isolation, purification, cultivation and preservation of actinomycetes. Methods in Microbiology, 4, 295-334. 